\title{
Fraternidades: Destinos e Impasses da Figura do Pai na Atualidade ${ }^{1}$
}

JOEL BIRMAN ${ }^{2}$

O artigo discute a fraternidade - uma questão teórica bastante presente tanto na tradição intelectual brasileira quanto na francesa - em vista das novas condições de mal-estar na atualidade, considerando como imperativo rever o descompasso existente entre os instrumentos psicanalíticos de escuta e as modalidades contemporâneas de sofrimento. Procede-se assim a uma releitura do laço fraterno frente ao entendimento deste como rivalitário tal como se dá na compreensão tradicional da estrutura edipiana, chegando-se, a partir de uma apreciação crítica do discurso freudiano, à concepção de diferentes modalidades de fraternidade.

Palavras-chave: Fraternidade; psicanálise; desamparo. 


\section{Uma Problemática Multidimensional}

A fraternidade é uma questão teórica bastante presente na atualidade, tanto na tradição intelectual brasileira quanto na francesa. As publicações no campo das ciências humanas evidenciam isso de diferentes maneiras. Um número crescente de artigos, ensaios e livros já se volta para a exploração desse campo. A simples consideração e evocação disso nos evidencia uma novidade importante, na medida em que nos revela a emergência de um outro horizonte conceitual para o trabalho do pensamento.

No entanto, a questão não se restringe a isso. Estamos aqui diante de algo bem mais abrangente, que se tece em surdina na nossa conjuntura histórica, cuja magnitude os pesquisadores farejam e procuram apreender no registro do pensamento. No campo estritamente intelectual e da pesquisa científica, transformações agudas se processam nos registros social e político de nossa contemporaneidade. A construção de uma ideologia dita humanitária, assim como, em contrapartida, o vazio em torno daquilo que se denomina comumente de solidariedade, são indicadores seguros desses processos mais amplos.

Tudo isso seriam signos evidentes dos destinos funestos pelos quais se perfila a problemática da soberania hoje ${ }^{3}$, no mundo globalizado e desregulado em que vivemos, que nos lança de maneira inevitável numa certa desproteção. Ao lado da crítica sistemática deste processo de mundialização (Bauman, 1998), começam já a se esboçar, de forma ainda balbuciante mas certamente resoluta, novas modalidades de cosmopolitismo (Hardt e Negri, 2000) e de internacionalismo (Derrida, 1994).

No que concerne à psicanálise, o mesmo começa também a acontecer e a se forjar, se bem que de maneira ainda tímida e tateante. Qual a razão para que exista essa evidente decalagem entre o discurso psicanalítico e os das demais ciências humanas, no que se refere a esta problemática?

Poder-se-ia dizer que isso seria um dos signos, dentre outros, em que se evidenciaria o conservadorismo presente no campo psicanalítico. A psicanálise deve afrontar o peso de seus fantasmas teóricos e das injunções transferenciais presentes no seu campo para poder se aproximar de maneira decisiva da problemática da fraternidade, na medida em que esta ocupa um estatuto de resto no discurso psicanalítico. Nas obras de Freud e de Lacan, assim como nas de Melanie Klein e Winnicott, o laço fraterno ocupa evidente posição de resto, não obstante o fato de ter sido objeto de teorização e de desenvolvimento temáticos ao longo da história da psicanálise. 
O laço fraterno como questão foi não apenas negligenciado na tradição psicanalítica, mas também colocado como secundário e até mesmo no limite considerado desprezível na economia psíquica, como conseqüência e desdobramento inevitáveis da prevalência atribuída à figura paterna (Freud, Lacan) ou à figura materna (escola inglesa). Este seria o obstáculo teórico maior, no campo psicanalítico, para que se possa atribuir à fraternidade positividade maior na economia subjetiva. Seria preciso atravessar esses fantasmas teóricos, nas suas devidas injunções transferenciais, para nos aproximar efetivamente disso e retirar a função fraterna no discurso psicanalítico desse limiar de resto.

Empreender hoje esse caminho teórico se impõe, no entanto, com certa urgência. Trata-se de um imperativo, porque as novas condições de malestar na atualidade assim se colocam no registro da experiência psicanalítica. É a clínica, portanto, que nos exige isso, se considerarmos o descompasso existente entre nossos instrumentos de escuta e novas modalidades de sofrimento que se apresentam na contemporaneidade.

\section{Rivalidade e Fraternidade}

Para realizar esse percurso teórico e atravessar o campo transferencialmente marcado pelos nossos fantasmas teóricos, é necessário indagar, inicialmente, sobre as linhas de força que podem delinear o laço fraterno, mesmo de maneira introdutória e, portanto, esquemática. Assim, a fraternidade não é um conceito simples e unívoco, como poderia talvez pensar um espírito apressado que pretendesse ir direto ao ponto. É preciso realizar um pequeno desvio, mesmo que tortuoso, para que não se conclua logo sobre algo tão controvertido como o laço fraterno. Está em pauta, antes de mais nada, a univocidade sempre presente na leitura desse conceito. Daí o plural no título deste ensaio, pelo qual quero aludir à existência de modalidades diferentes de fraternidade.

A fraternidade não pode ser restrita a uma dimensão estritamente familiar, apesar de estar sempre implícita nas leituras psicanalíticas sobre o tema. É claro que, na melhor tradição psicanalítica, a ordem familiar é sempre apreendida e difratada pela lógica edipiana, sendo as posições e as figuras inscritas na estrutura edipiana, nas suas diversas valências afetivas, que tornam a família uma configuração pregnante na realidade psíquica. A novidade introduzida pelo discurso psicanalítico, no campo das ciências humanas, se fundaria justamente aqui, isto é, a transversalidade operada pelo 
Édipo, que inscreve na realidade psíquica a dinâmica da ordem familiar. As identificações psíquicas seriam resultantes desse processo.

Ao lado disso, no entanto, a fraternidade se delineia ainda no registro do fantasma. Se a lógica desse não é incompatível com o cenário edipiano, insinua, em contrapartida, outra dimensão sempre presente no laço fraterno. Foi essa indubitavelmente a outra inovação trazida pela psicanálise na leitura do laço fraterno, que, se por um lado oferece materialidade psíquica à dinâmica edipiana, pelo outro, desenha também outra abrangência para esse laço no psiquismo. Por sua dimensão fantasmática, a problemática da fraternidade exige teoricamente que se considere devidamente a presença da economia libidinal nos laços sociais. É a indicação da presença dos signos contraditórios sempre evidenciados por esta economia o que define a especificidade teórica e metodológica da psicanálise.

Como decorrência disso, pode-se dizer que a leitura psicanalítica do laço fraterno implica também considerar suas dimensões ética e política. Esta leitura nos autoriza a isso, por se restringir ao registro edipiano ou por se abrir para o registro do fantasma.

Para isso, contudo, é preciso apreender também a fraternidade fora do registro da rivalidade, para dela depreender outra positividade. Estaria aqui o obstáculo teórico maior para que o discurso psicanalítico possa se aproximar da fraternidade de outra maneira, para poder atribuir a ela outro destino.

Com efeito, a fraternidade tem sido considerada apenas, na nossa tradição teórica, por seu traço rivalitário e no limite destruidor, sem que se enfatize devidamente que esta leitura é historicamente marcada. A interpretação cuidadosa do discurso freudiano nos permitirá indicar isso, de maneira concisa, em seus efeitos sintomáticos. Porém, o que a leitura deste discurso nos permitirá entrever, nas suas linhas e entrelinhas, é como a interpretação dos laços fraternos supõe também uma consideração crítica sobre os destinos da paternidade na subjetividade moderna. Vale dizer, a fraternidade rivalitária e mortífera está essencialmente ligada a uma disputa encarniçada dos irmãos pelo amor do pai. Não se pode considerar, portanto, o destino rivalitário da fraternidade sem que se sublinhe enfaticamente, ao mesmo tempo, o lugar estratégico ocupado pela figura do pai na disputa fraternal. Uma interpretação outra do laço fraterno, neste revelando outra positividade, pressupõe a superação deste obstáculo, ao mesmo tempo teórico e fantasmático.

Poder-se-ia indicar ainda que a rivalidade, enfatizada como decorrência 
única da fraternidade, está igualmente presente na tradição da escola inglesa. Mesmo que essa tenha empreendido o deslocamento crucial da figura paterna para a materna, como operador fundamental que seria presente na realidade psíquica, o que estaria em jogo aqui seria sempre a disputa mortal dos irmãos pelo amor materno. $\mathrm{O}$ mesmo obstáculo teórico se repete, pois, aqui, sem que ocorra qualquer modificação substantiva da problemática em pauta. Não tenho a intenção de examinar isso neste ensaio, contudo, mantendo apenas as tradições freudiana e lacaniana. Queria apenas indicar que, mesmo me atendo às tradições teóricas, a demonstração continuaria sendo igualmente válida para a escola inglesa da psicanálise.

Avancemos na leitura da figura paterna na psicanálise, para que se esbocem devidamente os obstáculos para outro discurso sobre a fraternidade. É preciso evocar que os destinos da imago paterna (Lacan, 1937) e do nome do pai (Lacan, 1981) se superpõem cada vez mais no nosso horizonte teórico e histórico. Não obstante suas diferenças conceituais, bem fundamentadas por Lacan, suas diversidades se apagam cada vez mais no imaginário contemporâneo, se considerarmos os novos desdobramentos do mal-estar na pós-modernidade. As modalidades novas de sofrimento psíquico evidenciam bem a impossibilidade de se separar na subjetividade atual os registros teóricos da imago paterna e do nome do pai.

Minha intenção é demonstrar, a partir de uma leitura crítica do discurso freudiano, como é possível conceber diferentes modalidades de fraternidade, desde que as consideremos em correlação estrita com os destinos da figura paterna na subjetividade. Para isso, no entanto, temos que destacar sempre em surdina os efeitos incisivos da desregulação, produzidos pela mundialização. As formas novas de sofrimento psíquico, existentes na atualidade, são a bússola e o leme que orientaram esta incursão crítica sobre a fraternidade.

\section{Da Proteção à Falha do Pai}

Como se sabe, Freud retomou em 1920, no célebre ensaio "Além do princípio do prazer", a teoria traumática das perturbações psíquicas que tinha deixado de lado em 1897. Esse abandono foi considerado a condição teórica de possibilidade para constituição da psicanálise como saber e como modalidade outra de experiência clínica. Para que se delineie bem o que significa essa retomada, é preciso definir devidamente não apenas o que é o trauma nesses dois momentos cruciais do discurso freudiano, como também o que está em jogo na leitura daquilo que é o traumático. É fundamental considerar 
o lugar estratégico atribuído à figura do pai no discurso freudiano. É justamente isso que está no cerne desta problemática, no fundamento das transformações do pensamento freudiano.

Assim, quando Freud disse a Fliess na sua correspondência que "não acreditava mais na sua neurotica" (Freud, "Lettres à Wilhem Fliess", 1973), afirmava ter perdido a convicção na teoria do trauma centrada na sedução (Freud, "L'étiologie...", 1973), na medida em que nenhuma narrativa de seus pacientes tinha o estatuto de acontecimento como concebera até então. As seduções que esses teriam sofrido, na tenra infância, não passariam de fantasmas, isto é, não seriam produzidos pela realidade material mas pela realidade psíquica (Freud, "L'interprétation des rêves...", 1976). Com isso, o discurso freudiano fundou a psicanálise como discurso na dita realidade psíquica, tendo no registro do inconsciente seu campo primordial de escuta (idem).

Para enunciar as coisas assim, no entanto, o discurso freudiano realizou uma verdadeira operação de salvação da figura do pai. Para deslocar o lugar da sedução como trauma, do registro do acontecimento para o do fantasma, Freud teria afirmado literalmente que não poderia aceitar que o pai pudesse ser uma figura realmente perversa, já que sedutor do infante (Freud, "Lettres à Wilhem Fliess", 1973). Enquanto personagem perverso engendrado pelo imaginário infantil, a sedução paterna poderia ser perfeitamente aceitável. Tudo isso constituiria o cenário perverso-polimorfo da realidade psíquica, mas não comprometeria a figura paterna no real, de forma que este foi forjado então como quem daria proteção ao infante e ao sujeito em geral.

Em 1920, contudo, caiu por terra a operação de salvação do pai empreendida por Freud, na medida em que na nova descrição da experiência psíquica aquele não poderia mais proteger o sujeito da experiência traumática. Desde então, a figura do pai foi delineada numa posição de falha no discurso freudiano, não porque fosse sedutor, mas porque não poderia mais antecipar os acontecimentos que pudessem ter um efeito traumático na subjetividade. Pode-se enunciar então que a nova configuração da figura do pai indica, ao lado da sua posição de falha, sua condição de falta, não podendo por isso mesmo o pai proteger a subjetividade do pior, como o pensamento freudiano acreditara firmemente nos seus primórdios.

Nesse contexto teórico o discurso freudiano formulou o conceito de pulsão de morte (Freud, "Au delà...", 1981). Assim, ao lado de Eros, no qual se incluiriam as pulsões sexuais, existiria também a pulsão de morte. Essa foi caracterizada pela sua dimensão de silêncio e pela ausência dos represen- 
tantes da pulsão. Existiriam aqui as intensidades, mas com suspensão dos representantes. O resultado disso é a presença estridente do ruído num campo imantado pelo silêncio. Vale dizer, a pulsão de morte indicaria a presença do excesso e da intensidade na subjetividade, justamente porque existiria uma falha na articulação representacional da pulsão (Freud, "Au delà...", 1981; Freud, "Le moi et le ça”, cap. II e III, 1981; Birman, 1999). Estariam reunidas assim as condições para a experiência traumática no sujeito, na medida em que seria este excesso ruidoso da pulsão, na falta da articulação representacional produzida pela figura paterna, a condição de possibilidade para o trauma.

Desenha-se então outra configuração da subjetividade, na qual o trauma é uma possibilidade sempre presente e virtual. Isso indicaria uma fragilidade inerente ao psiquismo, entreaberto por suas fissuras frente ao traumático. Por isso mesmo, o discurso freudiano forjou outra teoria da angústia, em 1926, em "Inibição, sintoma e angústia" (Freud, "Inhibition...", 1973), na qual a preocupação maior do sujeito seria antecipar-se a qualquer acontecimento que pudesse ter um efeito traumático. Com efeito, o psiquismo produziria antecipadamente angústia-sinal para evitar a desastrosa angústia traumática. O trauma seria agora uma possibilidade potencial sempre colocada no horizonte do sujeito, como decorrência da falta paterna. Vale dizer, a falha do pai se materializaria na sua impossibilidade de antecipação infalível, expondo então a subjetividade ao trauma.

A totalidade dessa reestruturação teórica, na leitura do psiquismo, teve como efeito fundamental um lugar outro atribuído ao registro econômico na metapsicologia freudiana. Passando a ocupar uma posição cada vez mais importante face aos registros tópico e dinâmico (Freud, "Pulsions...", 1968), o registro econômico, indicando o excesso e a pura pulsionalidade, seria a contrapartida agora da falha na articulação representacional da figura paterna (Freud, "Au delà...”, 1981). Ao registro econômico foi conferida posição estratégica na metapsicologia freudiana.

A compulsão de repetição seria a forma como o psiquismo poderia se estruturar, pela qual o sujeito buscaria ostensivamente ocupar posição ativa nos cenários do trauma e do excesso pulsional, procurando, pelo desprazer da repetição, antecipar-se à dor e a qualquer ameaça de morte psíquicas. Tudo isso, enfim, porque a subjetividade não poderia mais contar com a presença do pai protetor, na medida mesmo em que, desde então, a figura paterna teria a marca insofismável da falha. 


\section{Repetição e Formas de Subjetivação}

Essa viragem crucial no discurso freudiano já se antecipava antes dos anos 1920, evidenciada pela presença de signos esparsos mas sempre eloqüentes. Pode-se revelar isso não apenas nos escritos sobre a técnica psicanalítica, como também naqueles sobre a cultura.

Assim, em "Rememorar, repetir e elaborar", de 1914, o discurso freudiano indicava já os limites existentes no processo de rememoração na experiência analítica, evidenciando a presença, em contrapartida, da repetição. Esta já se impunha progressivamente na cena psicanalítica com toda a sua eloqüência e ruído, tal como será instituída posteriormente nos anos 20, passando a ocupar a posição estratégica atribuída até então à rememoração desde os primórdios da psicanálise (Freud, "Remémoration...", 1972).

O discurso freudiano procurou discriminar conceitualmente entre rememoração representacional e rememoração em ato, para afirmar sempre o primado do rememorar na cura analítica (idem). Porém, pode-se depreender que os limites do registro de representação estavam em questão, silenciavam e eram substituídos pela ruidosa repetição em ato. Articulavam-se já, nesse contexto, os signos inaugurais que serão reunidos posteriormente numa totalidade, por Freud, no conceito de compulsão à repetição e de pulsão de morte (Freud, “Au delà...”, 1981).

Rememorar em palavras e em atos não é exatamente a mesma coisa. Não obstante suas óbvias similaridades, evidenciam diferenças fundamentais. Uma concepção diversa da memória toma corpo, contrapondo uma perspectiva linear do tempo, fundada na relação sujeito/verbo/predicado, a uma outra, na qual a linearidade temporal implode em prol da fragmentação sintática do enunciado verbal. Com efeito, o verbo, como ato e gesto, no apelo irruptivo da compulsão, agora domina a totalidade da cena. O sujeito e o predicado se forjariam apenas em seguida, como desdobramentos da ação gestual do verbo.

Em "As pulsões e seus destinos", de 1915, o discurso freudiano procurou evidenciar tudo isso na configuração esboçada para a construção do circuito pulsional, ao propor as operações primordiais na sua constituição. Com efeito, na inversão da força da pulsão da posição de atividade para a de passividade, assim como na operação descrita como de retorno sobre a própria pessoa, a força como ato e gesto estaria sempre em pauta (Freud, "Pulsions...", 1968). Vale dizer, o verbo, na sua ruidosa compulsão, agente sintático primordial da ação, se desdobraria posteriormente nos enunciados 
proposicionais, presentes nas operações de recalque e da sublimação (idem).

Isso implica dizer que o discurso freudiano procurou esboçar a constituição das enunciações inconscientes a partir da oposição da força (Drang) da pulsão e do Outro (idem). Com efeito, as torções, retorções e derivações da primeira no campo deste constituiriam o circuito completo da pulsão e os enunciados constituídos pela conjugação do sujeito, do verbo e do predicado. $\mathrm{O}$ discurso freudiano não concebe mais o circuito da pulsão como formalmente construído, no qual a força da pulsão estaria desde sempre inscrita no registro da representação - como imaginara nos "Três ensaios sobre a teoria sexual" (Freud, "Trois essais...", 1962) -, mas como algo que se constituiria em ato pela compulsão, como gesto e verbo, no interstício constituído pela polaridade entre a força da pulsão e o Outro.

A falha e a falta da figura do pai estariam representadas nessa fissura crucial, materializadas no intervalo existente entre a força constituinte da pulsão e o circuito pulsional constituído. $\mathrm{O}$ abismo sempre presente entre essas construções metapsicológicas evidenciaria a falta da proteção paterna, expondo o sujeito à experiência traumática. A força pura da pulsão, destituída de qualquer articulação pelos objetos de satisfação e sem contar a hegemonia reguladora do princípio do prazer, se evidenciaria pelas figuras eloqüentes do excesso e da intensidade. Estamos, enfim, naquilo que o discurso freudiano enunciaria posteriormente, em 1920, como sendo o território regulado pelo além do princípio do prazer e pela presença da pulsão de morte (Freud, "Au delà...”, 1981).

Dito de outra maneira, a concepção de que existiria uma autonomia do registro à força, face ao dos futuros representantes pulsionais, fundaria o que o discurso freudiano formalizaria logo em seguida com os conceitos de pulsão de morte e da existência de um além do princípio do prazer (idem). Apenas nesse contexto, a formulação freudiana estabelecida desde os "Três ensaios sobre a teoria da sexualidade", segundo a qual o objeto seria o mais variável na pulsão (Freud, "Trois essais...", 1962), ganha pleno sentido. Com efeito, o objeto da força pulsional é variável e potencialmente infinito, na medida em que a figura do pai, como articulador e regulador do circuito da pulsão, é falho e expõe a subjetividade ao acaso dos encontros e dos desencontros objetais. Pelo viés do acaso, o discurso freudiano trouxe de volta a importância crucial da contingência e do acontecimento para a subjetividade. O trauma, portanto, estaria delineado pelo horizonte possível e virtual da subjetividade exposta ao acaso e à contingência. 


\section{Mal-estar e Modernidade}

As transformações fundamentais dos conceitos metapsicológicos, com as implicações inevitáveis que produziram na teoria da experiência psicanalítica, foram o correlato daquilo que o discurso freudiano procurou estabelecer simultaneamente na sua leitura sobre a cultura. Assim, as referidas falha e falta da figura do pai podem ser também encontradas nos escritos sobre a cultura, fundadoras dos ensaios metapsicológcios e técnicos. Os vazios presentes nestes podem ser agora preenchidos num percurso crítico, através dos textos em que Freud interpela a cultura pelos efeitos desta na subjetividade.

Pode-se enunciar que a morte realizou sua entrada triunfal na psicanálise pela figura bastante eloqüente da morte do pai. Num discurso dominado até então pela pregnância da sexualidade, Freud nos lançou não apenas na pregnância da morte na realidade psíquica, como também no lugar estratégico ocupado pela morte do pai na subjetividade. Como se sabe, apenas posteriormente a figura da morte se faria presente, sob a forma da existência da pulsão de morte, sendo antecedida conceitualmente pela afirmação do intervalo estabelecido entre a força e o circuito pulsional, no qual a repetição como compulsão passou a ocupar o lugar até então atribuído à rememoração na cura psicanalítica. É bastante importante sublinhar que a ficção histórica do pai morto não apenas introduziu a figura da morte no discurso freudiano, como também fundou as transformações metapsicológicas e técnicas ocorridas nesse contexto.

Assim, em "Totem e Tabu", o discurso freudiano nos apresenta a terrível cena do assassinato do pai da horda primitiva realizado por seus filhos (Freud, “Totem...”, 1975). Estes, sentindo-se mais fragilizados que o pai na sua força física e sempre ameaçados de morte por este, caso ansiassem desfrutar do gozo com as fêmeas da dita horda originária, decidiram reunir as suas parcas forças e matar o pai todo-poderoso. Constituíram desde então uma associação fraternal, baseada na solidariedade dos irmãos, tendo sempre como imperativo a presença da figura do pai como sombra, na qual todo aquele que pretendesse ocupar a posição originária do pai teria o mesmo destino funesto que este, isto é, a morte. No lugar do pai, agora morto e ausente, foi erigido um totem, como marca da origem de uma linhagem. Ao lado disso, a figura assassinada do pai seria sempre evocada como destino possível para todo aquele que quisesse pretender o monopólio do gozo e o poder absoluto na sociedade dos irmãos. 
Não obstante o discurso freudiano ter pretendido destacar a constituição da ordem humana como inscrita na ordem simbólica, pela passagem imemorial do registro da natureza ao da cultura, pelo limite inesquecível imposto à onipotência do pai primordial e à sua arrogância de pretender possuir o monopólio do gozo (idem), é evidente que aquele descreve a emergência e a constituição da modernidade na tradição ocidental. A sociedade moderna se teceu pela derrocada definitiva do poder absoluto e monárquico, que teve na decapitação do rei, no contexto da Revolução Francesa, seu símbolo maior e sua ritualização efetiva, rememorada desde então na nossa tradição.

A soberania absolutista foi definitivamente substituída pela soberania do povo. Como se sabe, tudo isso foi antecedido pela Revolução Inglesa, na qual o rei foi também decapitado, de forma que a soberania passou a ser dividida desde então entre as figuras do rei e a do parlamento (Hill, 1970).

Interessa destacar aqui que a descrição freudiana procurou empreender a narrativa épica do advento da modernidade, na qual uma modalidade de sociedade fundada nos laços fraternos substitui outra, centrada na figura do soberano como um. Desde então, este se inscreveria apenas no registro do fantasma e da realidade psíquica, como fonte permanente, para os filhos, da culpa pelo assassinato realizado e também como apelo de proteção, pelo signo imemorial, que seria da tradição.

Insisto na transformação radical daquele discurso, no qual a figura do pai se desloca de uma posição de proteção da subjetividade para outra; como fantasma, passa a se caracterizar pelos atributos da falta e a falha. Em tudo isso, a soberania se desloca do pólo do poder absoluto para o do poder relativo, em que a sociedade fraterna é a sua materialização eloqüente e a marca maior na modernidade.

A concepção de que a sociedade moderna seria individualista e não mais holista, na qual o indivíduo como valor estaria sempre no fundamento da modernidade e na base dos direitos humanos (Dumont, 1977 e 1983), evocado sempre nos preâmbulos das constituições francesa e norte-americana, seria outra maneira de dizer que a moderna sociedade no Ocidente se fundaria nos laços fraternais sem a presença da soberania absoluta. A morte por assassinato da figura do pai, nessa tradição, indicaria a desconstrução do holismo e a emergência histórica do individualismo. Seria também a fonte daquilo que o discurso freudiano enunciou posteriormente como o mal-estar na civilização (Freud, "Malaise...", 1971), que prefiro denominar mal-estar na modernidade (Birman, 2001), pelas razões acima enunciadas.

Com efeito, em 'A moral sexual 'civilizada' e a doença nervosa dos 
tempos modernos" (Freud, "La morale...", 1973), o discurso freudiano já indicava que o mal-estar que se plasmava sob a forma das perturbações do espírito era uma produção estrita da modernidade. As disfunções no registro moral, incidindo sobre a sexualidade, produziriam as perturbações psíquicas. A modernidade histórica que se trata aqui, no discurso freudiano, e não de uma pretensa transformação imemorial, sempre indicaria a passagem indelével do registro da natureza para o da cultura, no qual se contraporiam para sempre civilização e barbárie.

É preciso considerar que o significante civilização foi eminentemente produzido pela modernidade no Ocidente, assim como a oposição civilização e barbárie. Considerando não apenas a leitura acurada da constituição da palavra civilização desde o Renascimento até o século XIX (Starobinski, 1989), como também dos processos históricos e sociais que o constituíram, pode-se depreender facilmente sua modernidade (Elias, 1975). Em decorrência disso, o conceito de civilização foi inscrito no fundamento do discurso antropológico dos séculos XVIII e XIX (Duchet, 1995), assim como sua oposição ao de barbárie, como a história da antropologia social nos indica.

O discurso freudiano utiliza sempre os conceitos da civilização e de malestar na civilização no campo desses jogos de linguagem (Wittgenstein, 1961), no qual todos eles foram constituídos na modernidade. É disso então que se trata, não apenas para compreendermos devidamente o sentido semântico desses termos no discurso freudiano, mas principalmente para interpretarmos a transformação crucial que se processa no pensamento psicanalítico nesse contexto.

Portanto, ao substituir a figura do pai protetor pela do pai falho e faltante, o discurso freudiano se deslocou de uma concepção pré-moderna de cultura para uma outra, que seria propriamente moderna. A transformação de sentido da categoria pai seria o signo revelador disso na economia simbólica do pensamento freudiano. Apenas nesse contexto ele seria propriamente marcado pela modernidade, com as conseqüências metapsicológicas e técnicas acima indicadas.

Talvez esta afirmação surpreenda alguns leitores deste ensaio. Porém, para demonstrar isso, basta evocar a perplexidade de Freud com os efeitos destruidores revelados pela $1^{\text {a }}$ Grande Guerra. Sua fonte maior do aturdimento é constatar, horrorizado, como a civilização é a fonte permanente da barbárie, não estando no pólo oposto daquela, como pensara anteriormente. A ausência da figura do pai protetor seria a condição da barbárie e do malestar na modernidade. A falha e a falta na figura do pai seriam as condições 
de possibilidade da barbárie, lançando as figuras dos filhos numa rivalidade infinita e destruidora.

Em "Considerações atuais sobre a guerra e a morte", ensaio escrito em 1915 e que testemunha com vigor os efeitos destruidores até então inéditos da violência humana, Freud não pode mais compreender os descaminhos da civilização moderna e a derrocada da razão (Freud, "Considérations...", 1981). Pergunta-se, sempre inquieto e aturdido, como os representantes maiores da civilização ocidental, isto é, Alemanha, França e Inglaterra, poderiam perpetrar tal banho de sangue, como se o domínio da razão nada pudesse fazer frente ao imperativo passional da rivalidade guerreira. Seria tal perplexidade o signo maior da quebra definitiva do pai protetor, concebido até então como fundamento da civilização e da racionalidade. Enuncia-se uma nova figura do pai, com os atributos do filho e da falta, acompanhada do seu cortejo trágico de morte, destruição e violência, como marca inconfundível da modernidade.

Consideremos agora outras conseqüências metapsicológicas desta leitura nos seus efeitos sobre as formas de subjetivação no discurso freudiano. As figuras do desamparo e do masoquismo passaram a ocupar posições estratégicas no campo da subjetividade descrita neste discurso.

\section{Desamparo e Masoquismo}

O enunciado do conceito de pulsão de morte na viragem crucial dos anos 20 (Freud, "Au delà...", 1981), como conseqüência da desarticulação dos registros de força e dos representantes da pulsão na metapsicologia de 1915 (Freud, "Pulsions...", 1968), teve como desdobramento fundamental outra concepção da subjetividade, pela qual o desamparo estaria na base do psiquismo. A condição desamparada do sujeito, descrito pelo discurso freudiano, seria a contrapartida da nova forma, segundo a qual o pai passara a ser representado, isto é, sua figuração como falho e faltante. Pela consideração básica da condição psíquica do desamparo, as formas de subjetivação se constituiriam para produzir o sujeito enquanto tal.

Na metapsicologia, de 1915, o outro seria o pólo crucial para estruturação da força pulsional, delineando o horizonte para as formas de subjetivação. Os diferentes destinos da pulsão enunciados no discurso freudiano - transformação da atividade em passividade, retorno à própria pessoa, recalque e sublimação (Freud, "Au delà...", 1981) - seriam os diversos percursos constitutivos das formas de subjetivação. Com a nova dualidade pulsional 
dos anos 20, a pulsão de vida se inscreveria agora no pólo do Outro, estruturando as formas de subjetivação e se contrapondo à dissolução silenciosa promovida pela pulsão de morte (idem).

Ainda nesse contexto teórico, outro conceito de sublimação foi forjado (Freud, "Nouvelles...", 1936), segundo o qual não existiria mais oposição entre erotismo e sublimação, tal como enunciado no início do percurso freudiano (Freud, "Trois essais...", 1962). Concebidos como operações destinadas à articulação dos registros da força, do objeto e da representação da pulsão, a sublimação e o erotismo seriam formas diversas da pulsão de vida se contrapondo à pulsão de morte. Conseqüentemente, erotizar e sublimar seriam gramáticas diversas das formas de subjetivação, pelas quais o psiquismo se defrontaria criativamente com sua nova condição de desamparo.

Porém, a convivência trágica com a condição desamparada se transformou na problemática fundamental da subjetividade. Por isso mesmo, diante da dor que isso implica, o sujeito buscaria a todo custo se defender dessa condição, denegando-a, recusando-a e a rejeitando. Assim, passa pelas figuras do pai ideal e do supereu, como defesas face ao desamparo. Com isso, portanto, a tragicidade da condição desamparada da subjetividade, delineada no percurso final do discurso freudiano, se transformou em drama, pelo apelo desesperado de proteção que passa a ser feito pelo sujeito à figura do pai falho e faltante, que se inscreve no psiquismo pelos registros do pai ideal e do supereu. É nesta perspectiva teórica que se deve interpretar a afirmação recorrente de Freud, de que na neurose existiria sempre a "nostalgia do pai", que se materializaria psiquicamente pela presença gigantesca das formações psíquicas enunciadas (Freud, "Malaise...", 1971).

Como conseqüência, o masoquismo se destaca como cena psíquica fundamental no discurso freudiano, passando a dominar toda a psicopatologia dele decorrente. Sempre presente nas modalidades neurótica, perversa e psicótica de funcionamento psíquico, de maneiras diferentes, o masoquismo seria desde então a figura-chave da psicopatologia freudiana. Tudo passaria pela cena do masoquismo, prima donna da realidade psíquica propriamente dita.

Em "O problema econômico do masoquismo", de 1924, o discurso freudiano não apenas enunciou que o masoquismo seria primário e o sadismo sempre secundário (Freud, "Le problème...", 1973), invertendo assim suas formulações anteriores (Freud, "Pulsions...", 1968), como também formulou uma cartografia do masoquismo até então inexistente. Entre os masoquismos erógeno, moral e feminino, essa cartografia foi traçada de maneira precisa 
e inequívoca (Freud, "Le problème...”, 1973), configurando as novas formas de relação da subjetividade no contexto trágico do desamparo e das defesas dramáticas contra ele constituídas.

Assim, se o dito masoquismo erógeno evidencia com eloqüência a condição desamparada do sujeito na inexistência da figura do pai protetor, os masoquismos moral e feminino visariam a um apagamento da sua condição de desamparo, pela busca desesperada da proteção pela mediação da figura do pai. Com efeito, através deles o sujeito se subordinaria sempre a um outro, numa posição degradante de servidão, para evitar a condição fundamental do desamparo. As figuras do supereu e do eu ideal se agigantariam no psiquismo, assim, como formas da presença do pai ideal e protetor.

Pode-se igualmente demonstrar isso se nos deslocarmos do registro da estrutura psíquica para o do fantasma no discurso freudiano. Com efeito, em "Bate-se numa criança", esse discurso procurou articular no registro estritamente fantasmático o apelo do infante à figura do pai ideal, no contexto marcado pela mortífera rivalidade fraterna, em nome do amor do pai (Freud, "Un enfant...”, 1972). A condição masoquista foi enunciada no centro da cena psíquica, tendo o sujeito agora nas figuras do pai e dos irmãos os personagens centrais para traçar e fixar seu lugar degradado naquela condição.

A fraternidade, fundada tanto na figura do pai ideal quanto no supereu, seria uma defesa crucial contra a condição de desamparo do sujeito, constituindo apenas uma de suas modalidades. Foi apenas essa forma mortífera de laço fraternal que a comunidade psicanalítica destacou até hoje, tanto na tradição inglesa como francesa, como já afirmado. A busca pelo amor exclusivo do pai, na condição fundamental de desamparo do sujeito e da inexistência da figura do pai protetor, produziria como conseqüência a competição mortal entre os irmãos.

Em seguida, pode-se destacar, nas entrelinhas deste ensaio, que a perda da autoridade do pai seria a contrapartida da rivalidade fraterna fundada na defesa do sujeito contra o desamparo. Na narrativa freudiana desse cenário fantasmático, seria outra versão da figura enfraquecida do pai na modernidade. A figura paterna se faz presente pelo registro exclusivo da força e não pelo da palavra e da linguagem. Nos registros psíquicos do pai ideal e do supereu, a figura do pai se apresenta marcada pela ferocidade, implicando sempre submissão do sujeito. Tudo isso nos remete, enfim, para os masoquismos feminino e moral há pouco referidos, como modalidades privilegiadas de defesa que são contra a condição de desamparo da subjetividade na modernidade. 
Estaríamos aqui confrontados com uma e apenas uma modalidade de fraternidade produzida pela modernidade. $\mathrm{O}$ laço fraterno seria bastante bem descrito no discurso freudiano, como marca eloqüente da nostalgia do sujeito pela figura paterna. Entretanto, essa não seria a única forma possível de existência do laço fraterno, já que este poderia ser engendrado de outra maneira pelo sujeito, desde que pudesse reconhecer efetivamente sua condição de desamparo, tendo na figura do pai falho seu correlato estrutural e funcional. A constituição das novas modalidades de laço fraterno é o que a atualidade nos exige agora, como um imperativo ético e político, nos registros ao mesmo tempo individual e coletivo. No entanto, é preciso reconhecer plenamente nossa condição básica da insuficiência (Birman, 2000 e 2001), outra maneira de enunciar o conceito freudiano de desamparo e da figura faltante do pai na modernidade. O que se impõe para nós, hoje, é a desconstrução da figura da servidão voluntária que nos persegue e obceca desde a aurora dos tempos modernos, no século XVI.

\section{Morte do Pai, Morte de Deus e Desencantamento do Mundo}

A servidão voluntária era já descrita por La Boétie, no Renascimento, na emergência do mundo moderno, de maneira sempre espantosa e inquietante (La Boétie, 1983). Indicava como, na inauguração da modernidade, já se estaria esvaziando simbolicamente a figura do pai, por um lado, restabelecendo-a como um fantasma, por outro, fundada sempre nos registros da força e da submissão. Por este viés, a condição de desamparo era silenciada pelo sujeito, pelo apelo recorrente que fazia ao poder soberano para que o protegesse disso. Tal estrutura, inscrita ao mesmo tempo nos registros antropológico, psíquico e político, manteve-se com variações durante séculos na tradição do Ocidente, sobrevivendo até mesmo aos imperativos de fraternidade e de solidariedade forjados pelas Revoluções Francesa e Russa (Birman, 1999). Essa mesma servidão e assujeitamento foram reencontrados no discurso freudiana, sob a forma dos masoquismos, nas pessoas que sofrem, que evitavam a todo custo, na modernidade, a convivência trágica com sua condição de desamparo.

É preciso enfatizar que o desamparo, como paradigma da subjetividade na modernidade, foi o efeito crucial e o preço que pagamos por termos assumido o poder de desafiar o pai, nos registros simbólico e político. Construímos uma civilidade fundada na ciência e na racionalidade, em oposição radical à tradição teológica fundada na figura de Deus, desde que o ceticis- 
mo de Montaigne (1962) e a filosofia de Descartes (1949) nos lançaram propriamente em outro mundo, no qual a condição de desamparo seria constitutiva do sujeito (Freud, "Malaise...", 1971). O discurso freudiano pôde teorizar tudo isso com a psicanálise, formulando as teses sobre o mal-estar na civilização e na modernidade, considerando justamente o fim da linha, isto é, seus efeitos desastrosos na subjetividade moderna.

Assim, é preciso considerar que a assunção, já tardia, pelo discurso freudiano da figura do pai assassinado pelos filhos foi a versão psicanalítica daquilo que fundou a modernidade. Porém, o que Freud descreveu desta maneira encontrou sua contrapartida também em outras disciplinas, no contexto histórico de constituição da psicanálise. O discurso filosófico, com Nietzsche, enunciara que a modernidade tinha na morte de Deus seu fundamento (Nietzsche, 1971), assim como Weber sublinhava que o desencantamento do mundo estava na base do mundo moderno (Weber, 1964). O desencantamento do mundo descrevia a existência de um mundo sem deuses, que não mais nos protegeriam, no qual o desenvolvimento das racionalidades científica e burocrática foi seu correlato. A tese de Nietzsche foi desenvolvida por Heidegger na sua crítica da tradição ontoteológica da filosofia do Ocidente, procurando destacar a emergência dos discursos da ciência e da técnica (Heidegger, 1962). Enfim, o discurso freudiano estaria aludindo à morte de Deus, sob a forma da morte do pai primordial, como fundamento antropológico do desamparo na subjetividade moderna.

Dito de outra maneira, o mal-estar descrito no discurso freudiano como marca do sujeito na modernidade encontra nas diferentes leituras seu fundamento e reconhecimento. Face à sua condição de desamparo, o sujeito apela dramaticamente para a proteção das figuras do pai ideal e do supereu. Porém, com isso também, o sujeito passa a se colocar numa posição degradante de submissão e de servidão voluntária. Os fantasmas presentes na narrativa "Bate-se numa criança" passam a habitar seu imaginário, pois os masoquismos feminino e moral seriam os efeitos mortíferos de seu assujeitamento. Ao lado disso, o laço fraterno se amesquinha e se degrada, assumindo apenas a forma da ferocidade rivalitária, na qual a figura paterna também se esvazia de qualquer autoridade simbólica, reduzindo-se ao registro brutal da força.

Estamos bem no fundamento do que La Boétie enunciou como servidão voluntária, à medida que os masoquismos feminino e moral seriam as versões freudianas daquele. Com efeito, a entrega degradante do sujeito ao outro para que esse possa gozar como quiser do seu corpo e espírito, para 
que assim possa não conviver com o seu desamparo e ser protegido, é o que caracteriza a condição masoquista propriamente dita. Com isso, as figuras do pai ideal e de supereu se agigantam no psiquismo, subordinando o sujeito aos seus imperativos mortíferos.

Tudo isso se inscreveu devidamente no discurso político da modernidade, marcando a ferro e fogo nossa história. Os totalitarismos foram suas construções no registro político. Com efeito, tanto no stalinismo quanto no nazismo, o sujeito, nos registros individual e coletivo, buscou restaurar a figura do pai ideal e do supereu, para se proteger do mal-estar e das incertezas provocadas pelo desamparo. Com isso, restaurou a figura do pai protetor, promovendo as tiranias conhecidas em nossa triste modernidade. Como desdobramento, a fraternidade construída no contexto da servidão voluntária perdeu qualquer marca de solidariedade e se configurou de forma ferozmente genocida, nos nacionalismos, etnocentrismos e imperialismos que permearam a modernidade.

\section{Amizade e Solidariedade}

Depreende-se então que a problemática freudiana do mal-estar na modernidade exige de todos nós, de maneira imperativa, uma solução que se inscreve em diferentes registros, quais sejam, o da singularidade psíquica, o dos laços sociais e o político. Uma leitura ética do mal-estar perpassa esses diferentes registros. Isso se destaca de forma pregnante no horizonte interpretativo do discurso freudiano, tal como enunciado neste ensaio. Aqui, uma outra leitura da fraternidade, deslocando-nos decididamente de uma versão rivalitária e mortífera, mostrou-se possível.

A contrapartida, no entanto, é o reconhecimento de que o desamparo estaria no fundamento da condição humana na modernidade. Isso constituiria a matéria-prima dos novos laços fraternais, em que a solidariedade e a amizade poderiam ser os eixos para a reconstituição dos laços sociais. Seria necessário reconhecermos, contudo, que a feminilidade foi outra maneira de o discurso freudiano enunciar o conceito de desamparo.

Assim, no ensaio "Análise com fim e análise sem fim", de 1937, Freud procurou indicar a existência da feminilidade como fundamento do psiquismo, que produziria horror igualmente nos homens e mulheres (Freud, "L'analyse...", 1986), justamente porque no registro do desamparo e da feminilidade estes não poderiam se proteger mais com o falo, seja sob a forma do supereu seja sob a do pai ideal. 
Por este viés, poderíamos ainda, numa perspectiva genealógica da subjetividade moderna fundada na pesquisa teórica de Foucault (1976), retomar uma outra leitura crítica do discurso freudiano. Desta maneira, novos laços fraternais poderiam ser tecidos, nos quais a amizade e a solidariedade se destacariam como suas marcas fundamentais. Com isso, a trágica condição da vida nua na subjetividade contemporânea, descrita com agudeza por Agamben (1997), poderia ser reinterpretada pelos conceitos freudianos de desamparo e feminilidade, indicando radicalmente a posição descentrada do sujeito, enunciado por Freud, no contexto do esgarçamento da soberania na atualidade.

\section{Referências Bibliográficas}

AGAMBEN, G. Homo sacer. Paris: Seuil, 1997.

BAUMAN, Z. Globalisation: the human consequences. Cambridge: Polity Press, 1998.

BIRMAN, J. A servidão na psicanálise. In: VAZ RODRIGUES, G. (Coord.). Fascínio e servidão. Belo Horizonte: Autêntica, 1999.

BIRMAN, J. Insuficientes: um esforço a mais para sermos irmãos!. In: KEHL, M. R. (Coord.). Função fraterna. Rio de Janeiro: Relume Dumará, 2000.

BIRMAN, J. Les enjeux de l'interprétation en psychanalyse: un essai sur Freud. Paris: L'Harmattan, 1999.

BIRMAN, J. Mal-estar na atualidade. Rio de Janeiro: Civilização Brasileira, 2001.

BIRMAN, J. Servidão, fidelidade, ancestralidade. In: LO BIANCO, A. C. (Coord.). Formações teóricas da clínica. Rio de Janeiro: Contracapa, 2001. DERRIDA, J. Politiques du l'amitié. Paris: Galilée, 1994.

DESCARTES, R. Discours de la méthode. In: DESCARTES, R. Oeuvres et lettres de Descartes. Paris: Pleiade, 1949.

DESCARTES, R. Méditations. In: DESCARTES, R. Oeuvres et lettres de Descartes. Paris: Pleiade, 1949.

DUCHET, M. Anthropologie et histoire au siècle des Lumières. Paris: Albin Michel, 1995.

DUMONT, L. Essais sur l'individualisme. Paris: Seuil, 1983. 
DUMONT, L. Homo aequalis. Paris: Gallimard, 1977. v. 1.

ELIAS, M. La civilisation des moeurs. Paris: Calmamm Lévy, 1975.

FOUCAULT, M. Volonté de savoir. Paris: Gallimard, 1976.

FREUD, S. Au-delà du principe de plaisir. In: FREUD, S. Essais de psychanalyse. Paris: Payot, 1981.

FREUD, S. Considérations actuelles sur la guerre et sur la mort. In: FREUD,

S. Essais de Psychanalyse, 1981.

FREUD, S. Inhibitiohn, symptôme et angoisse. Paris: PUF, 1973.

FREUD, S. L'analyse avec fin et l'analyse sans fin. In: FREUD, S. Résultats, idées, problèmes. Paris: PUF, 1986. v. 2.

FREUD, S. L'étiologie de l'hystérie. In: FREUD, S. Névrose, psychose et perversion. Paris: PUF, 1973.

FREUD, S. L'interprétations des rêves. Paris: PUF, 1976. cap. 7.

FREUD, S. La morale sexuelle "civilisée" et la maladie nerveuse des temps modernes. In: FREUD, S. La vie sexuelle. Paris: PUF, 1973.

FREUD, S. Le moi et le ça. In: FREUD, S. Essais de Psychanalyse, 1981.

FREUD, S. Le probléme économique du masochisme. In: FREUD, S. Névrose, psychose et perversion. Paris: PUF, 1973.

FREUD, S. Lettres à Wilhem Fliess. Notes et Plans (1887-1902). In: FREUD, S. La naissance de la psychanalyse. Paris: PUF, 1973.

FREUD, S. Malaise dans la civilization. Paris: PUF, 1971.

FREUD, S. Nouvelles conférences sur la psychanalyse. Paris: Gallimard, 1936.

FREUD, S. Pulsions et destins des pulsions. In: FREUD, S. Metapsychologie. Paris: Gallimard, 1968.

FREUD, S. Remémoration, repétition et élaboration. In: FREUD, S. Les écrits techniques. Paris: PUF, 1972.

FREUD, S. Totem et Tabou. Paris: Payot, 1975. cap. 4.

FREUD, S. Trois essais sur la théorie de la sexualité. Paris: Gallimard, 1962.

FREUD, S. Un enfant est battu: Contribution à la connaissance de la genèse des perversions sexuelles In: FREUD, S. Les écrits techniques. Paris: PUF, 1972.

HARDT, M.; NEGRI, A. Empire. Paris: Exils, 2000.

HEIDEGGER, M. Chémins qui ne menènt nulle part. Paris: Gallimard, 1962.

HILL, C. God's englishman. Oliver Cromwell and the English Revolution. Londres: Penguim Books, 1970. 
LA BOÉTIE, E. Discours de la servitude voluntaires. Paris: Flammarion, 1983.

LACAN, J. Fonction et champ de la parole et du langage en psychanalyse. In: LACAN, J. Écrits. Paris: Seuil, 1966.

LACAN, J. Les complexes familiaux dans la formation de l'individu. In: LACAN, J. Encyclopédie française sur la vie mentale. v. VII. Paris: Seuil, 1937.

LACAN, J. Les psychoses. Le Séminaire de Jacques Lacan. Paris: Seuil, 1981. v.3.

MONTAigne, M. Essais. In: MONTAIGNE, M. Oeuvres complètes. Paris: Pleiade, 1962.

NIETZSCHE, M. Genéalogie de la morale. Paris: Gallimard, 1971.

STAROBINSKI, J. Le mot civilisation. In: STAROBINSKI, J. Le remède dans le mal. Paris: Gallimard, 1989.

WEBER, M. L'éthique protestante et l'esprit du capitalisme. Paris: Plon, 1964.

WITTGENSTEIN, L. Investigations philosophiques. In: WITTGENSTEIN, L. Tractatus logico-philosophicus suivi de Investigations Philosophiques. Paris: Gallimard, 1961.

\section{NOTAS}

1 Este ensaio se baseou em conferência realizada em Paris, em 6 de outubro de 2001, no Colóquio Franco-Brasileiro organizado pela Unité de Recherche Psychogènese et Psychopathologie da Université Paris XIII, intitulado Modernité des liens fraternels et conjugaux.

2 Psicanalista, membro do Espace Analytique, presidente do Espaço Brasileiro de Estudos Psicanalíticos, professor titular do Instituto de Psicologia da Universidade Federal do Rio de Janeiro e professor adjunto do Instituto de Medicina Social da Universidade do Estado do Rio de Janeiro.

3 Sobre isso, ver: Les temps modernes, n. 610; Le théâtre de la mondialisation: acteurs, victimes, laissez-pour-compte. Paris, Janvier-février, 2000; Les temps modernes, n. 610. La souveraineté. Horizons et figures de la politique, n. 610. Paris, septembre-octobre-novembre 2000. 
Sibling Relations: Destinations and Impasses in the Contemporary Father Figure

This article discusses sibling relations - recently a theoretical issue with a strong presence in both the Brazilian and French intellectual traditions - in light of new conditions of discontent in contemporary society, considering the imperative of reviewing the prevailing mismatch between psychoanalytic listening tools and new contemporary modalities of suffering. The article thus conducts a re-reading of the sibling rivalry portrayed in fraternal relations according to the traditional understanding of the Oedipal structure, thereby performing a critical review of Freudian discourse to reach a conceptualization of different modalities of sibling relations.

Keywords: Sibling relations; psychoanalysis; helplessness.

Recebido em: 30/09/2002.

Aprovado em: 02/06/2003. 